\title{
A New Supramolecular Route for Using Rod-Coil Block Copolymers in Photovoltaic Applications
}

\author{
By Nicolas Sary, Fanny Richard, Cyril Brochon, Nicolas Leclerc, \\ Patrick Lévêque, Jean-Nicolas Audinot, Solenn Berson, Thomas Heiser, * \\ Georges Hadziioannou, * and Raffaele Mezzenga*
}

The growing interest for renewable energy technologies, such as photovoltaic (PV) devices, combined with the need for low-cost processing, have contributed to the quick expansion of organic PVs. $^{[1]}$ Since the pioneering work of Tang ${ }^{[2]}$ on electron-donor (D)/electron-acceptor (A) double-layer devices, considerable efforts have focused on the development of bulk D/A heterojunctions based on photoactive compounds of electron-donating conjugated polymers and fullerene derivatives. ${ }^{[3-6]}$ In these devices the organic components form, throughout the entire active layer, nanometer-sized D and A domains at whose interfaces photogenerated excitons can dissociate into free charge carriers, which in turn are driven to the collecting electrodes by the built-in electric field of the device. ${ }^{[7,8]}$ Applying this methodology to polythiophene/fullerene blends led to PV devices with power conversion efficiencies (PCEs) around 5\%. ${ }^{[9,10]}$

[*] Prof. T. Heiser, Dr. P. Lévêque

Institut d'Electronique du Solide et des Systèmes

Centre National de la Recherche Scientifique,

Université de Strasbourg

23, Rue du Loess, 67037 Strasbourg (France)

E-mail: thomas.heiser@iness.c-strasbourg.fr

Prof. G. Hadziioannou, ${ }^{[+]}$Dr. F. Richard, Dr. C. Brochon ${ }^{[+]}$

Dr. N. Leclerc

Laboratoire d'Ingénierie des Polymères pour les

Hautes Technologies

Université de Strasbourg, Ecole Européenne de

Chimie Polymères et Matériaux

25, Rue Becquerel, 67087 Strasbourg (France)

E-mail: hadzii@ecpm.u-strasbg.fr

Prof. R. Mezzenga, Dr. N. Sary

Department of Physics and FRIMAT Center for Nanomaterials, University of Fribourg

Ch. Musée 3, CH-1700 Fribourg (Switzerland)

E-mail: raffaele.mezzenga@unifr.ch

Prof. R. Mezzenga

Nestlé Research Center, Vers-Chez-Les-Blanc

1000 Lausanne 26 (Switzerland)

Dr. J.-N. Audinot

Science and Analysis of Materials Department

Public Research Centre Gabriel Lippmann

41 rue du Brill, L-4422 Belvaux (Luxembourg)

Dr. S. Berson

Laboratoire des Composants Solaires, Institut de l'Energie Solaire Commissariat à l'énergie atomique BP 332

50 Avenue Du Lac Léman, 73377 Le Bourget Du Lac (France)

$\left.{ }^{+}\right]$Present address: Laboratoire de Chimie des Polymères Organiques (LCPO) CNRS/UNIV. Bordeaux1/ENSCBP-16 av. Pey-Berland-33607 PESSAC Cedex (France); E-mail (from January 2010): hadzii@enscbp.fr
Despite this success, polymer/fullerene blends suffer from two major drawbacks: a poorly controlled D/A domain size distribution and inherent morphological instability. The D and A domains generally originate from spinodal decomposition occurring during the film formation from a spin-coated solution and are therefore strongly dependent on the processing conditions and difficult to control. ${ }^{[1]}$ Moreover, macrophase separation of both blend components may occur within the active layer upon extended device operation and considerably modify the as-deposited thin film morphology. ${ }^{[3]}$ The resulting domain size can ultimately become much larger than the exciton diffusion length (about $10 \mathrm{~nm}$ in semiconducting polymers ${ }^{[12,13]}$ ) and diminish the device performances.

The use of rod-coil block copolymers as photoactive material in bulk heterojunction devices is a possible way to overcome these drawbacks. Rod-coil block copolymers are indeed well known to self-assemble through microphase separation into highly ordered nanostructures that are thermodynamically stable and exhibit spatial periodicities on the $1-10 \mathrm{~nm}$ length scale. ${ }^{[14-19]}$ Block copolymers composed of an electron-donating and an electronaccepting block are therefore particularly interesting for PV applications and are presently studied worldwide by several research groups. ${ }^{[20-37]}$ Particularly, rod-coil block copolymers using poly[(2,5-di(2-ethyl)hexyloxy)-1,4-phenylenevinylene] (DEH-PPV) as electron donor and various coil blocks (such as polystyrene or polybutylacrylate) with covalently linked fullerene moieties as electron acceptor have been investigated intensively. ${ }^{[23-28]}$ Although these studies have given considerable insight into the physics of copolymer self-assembly, their efficient utilization as the active layer in PV devices has not yet been fully demonstrated.

In the present work, we report on the thin film nanostructure of blends of regio-regular poly(3-hexylthiophene)-block-poly(4vinylpyridine) (P3HT-b-P4VP) rod-coil block copolymers with [6,6]-phenyl-C61-butyric acid methyl ester (PCBM) and on the optoelectronic properties of preliminary PV devices made thereof.

We anticipate that a conjugated polymer with strong $\pi-\pi$ stacking interactions, such as regio-regular P3HT (rr-P3HT), used as the rod block should stabilize the copolymer nanostructure in the presence of fullerene derivatives and allow good hole transport. Furthermore, we show that the utilization of a P4VP coil block demonstrates a new way to form electronacceptor domains within a block copolymer self-assembled nanostructure. Indeed, polyvinylpyridines are known to experience weak supramolecular interactions with electron-deficient chemical species. ${ }^{[38-40]}$ These interactions would make free $\mathrm{C}_{60}$ molecules preferentially accumulate within the coil domains and, 
when combined with an electron-donating rod block, lead to the endeavored D/A interpenetrated networks. Also, in the case of block copolymer/fullerene blends, the copolymer microphase separation has been found to be less affected by the $C_{60}$ crystallization than for fullerene-grafted block copolymers. ${ }^{[34,39]}$ In particular, the pristine DEH-PPV-b-P4VP nanostructure was shown to be preserved when blended with $10 \% \mathrm{C}_{60}$ and to be thermally stable up to at least $16 \mathrm{~h}$ at $180^{\circ} \mathrm{C} \cdot{ }^{[39]}$ Finally the PCBM fullerene derivative was chosen for its high solubility in common solvents.

In this paper, special emphasis is put on the copolymer nanostructure, the morphology thermal stability, and the device properties, for different PCBM contents. We find that the P3HT ordering as well as the copolymer nanostructure can be maintained even at relatively large fullerene contents (36 vol\%) and that the thermal stability is dramatically improved in comparison to P3HT:PCBM blends. Finally, we show that a high photon-to-current conversion efficiency (above 40\%) and an overall PCE of $1.2 \%$ can be reached even with non-optimized PV devices, which positions the present solar cells among the best-performing PV devices having block copolymers as the major constituent in the active layers.

Figure 1a sketches the blend of the P3HT-P4VP block copolymer and PCBM studied in the present work. P3HT-P4VP has been obtained by anionic polymerization of 4-vinylpyridine and quenching with an aldehyde endfunctionalized P3HT. This route has been adapted from the synthesis of a PPV-based block copolymer previously described $^{[17,18]}$ and will be discussed in detail in a separate manuscript. The synthesized diblock copolymer (Fig. 1a) has a total molecular weight of $11.6 \mathrm{~kg} \mathrm{~mol}^{-1}$ and a $\mathrm{P}_{3} \mathrm{HT}_{52}-\mathrm{P}_{4} \mathrm{VP}_{28}$ architecture. Three series of P3HT-P4VP:PCBM blends, based on either 8,17 , and $36 \%$ volume fractions of PCBM were investigated. These blends and related PV devices are hereafter referred to as C8, C17, and C36. Standard P3HT:PCBM (1:1 weight ratio) blends were used as reference material. The details about film formation and device elaboration procedures are described in the Experimental Section.

The thin film nanostructure was investigated by transmission electron microscopy (TEM) and UV-vis absorption spectroscopy. PV devices using the $\mathrm{C} 8, \mathrm{C} 17$, and $\mathrm{C} 36$ blends as photoactive layer were elaborated according to both, standard (Fig. 1b) and inverted (Fig. 1c) configurations, for reasons which will become evident in what follows. The devices current-voltage characteristics were measured under darkness and under air mass 1.5 (AM1.5) illumination. The incident photon-to-current conversion efficiency (or IPCE) of the device was measured with a standard experimental set-up.

According to Ikkala and co-workers, ${ }^{[38]}$ each PCBM molecule can form noncovalent bonds with up to six 4-vinylpyridine (4VP) monomer units. Considering the number of PCBM molecules per 4VP monomer unit actually present in the active layers, this is only possible in the case of $\mathrm{C} 8$, whereas at higher PCBM content only partial binding to 4VP units can be achieved.

Figure 2 compares the thin film morphology of the $1: 1$ P3HT:PCBM blend to that of the C36 copolymer blend, after annealing at $150^{\circ} \mathrm{C}$ for either $30 \mathrm{~min}$ (Fig. 2a,c) or $24 \mathrm{~h}$ (Fig. 2b,d). The morphologies of the corresponding pristine P3HT-P4VP block copolymer are shown in the insets. After $30 \mathrm{~min}$ of a)

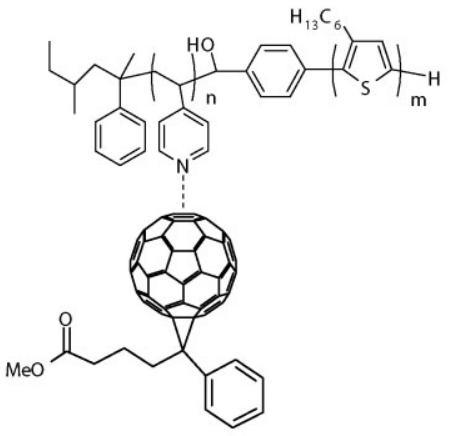

b)

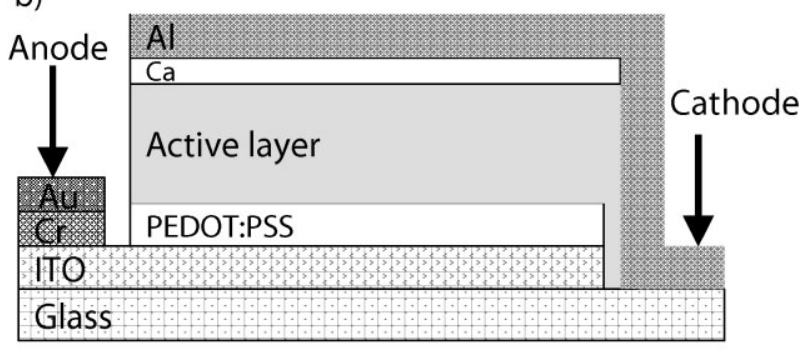

c)

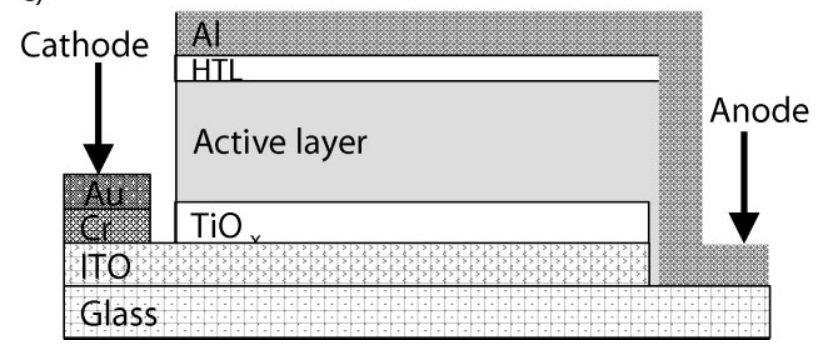

Figure 1. a) P3HT-P4VP block copolymer/PCBM compound used for the polymer bulk heterojunction active layer: b) standard and c) inverted PV device structure used in this study. (PEDOT:PSS = poly(3,4-ethylenedioxythiophene): poly(styrenesulfonate), ITO=indium tin oxide, $\mathrm{HTL}=$ hole transport layer).

annealing, both the reference and block copolymer active layers exhibit comparable nanostructures, with a high level of mixing of the blend components. Major differences arise however after longer annealing times. Micrometer-sized dark domains, which most likely correspond to PCBM crystallites, are present in the PCBM:P3HT blend and point out significant macrophase separation. On the other hand, the C36 nanostructure shows an increased structural order and no formation of microdomains, maintaining a morphology similar to that of the pristine block copolymer (see Fig. 2 insets). These results therefore suggest that i) the high PCBM loading does not perturb the copolymer self-assembly and ii) the block copolymer:PCBM system provides a significantly improved structural stability. Most importantly, these findings show that supramolecular bonding between the fullerene and P4VP coil block avoids the formation of macroscopic fullerene crystals without hampering the copolymer self-assembly. This behavior contrasts with that of previously reported fullerene-grafted block copolymer self-assembly. ${ }^{[34]}$ Furthermore, from the pronounced thermal stability of the 


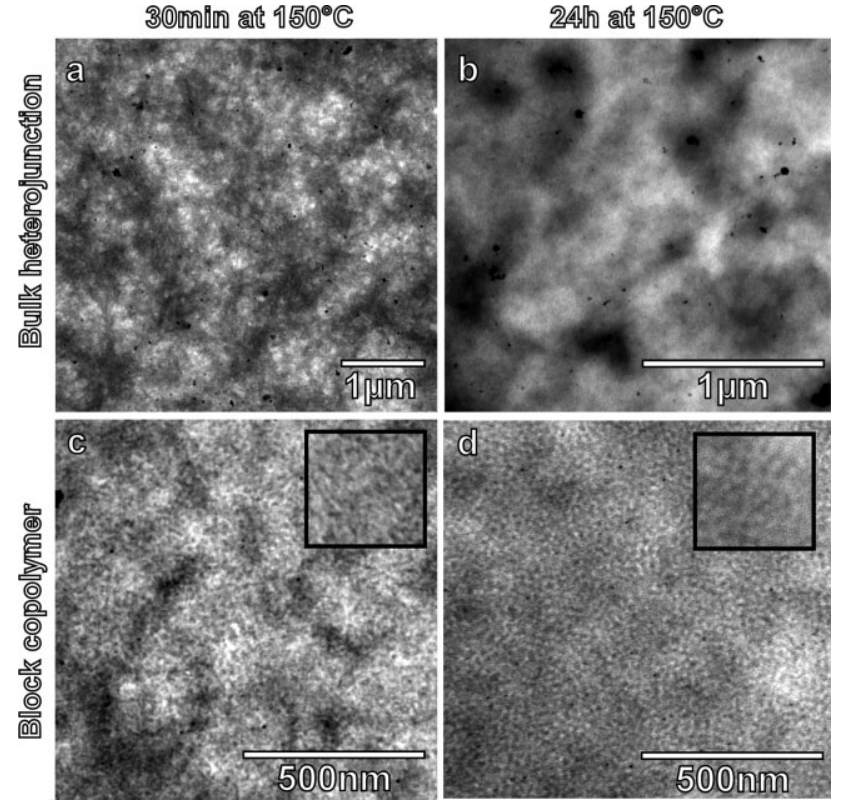

Figure 2. TEM images of $\mathrm{P} 3 \mathrm{HT}: \mathrm{PCBM}(1: 1)$ and $\mathrm{P} 3 \mathrm{HT}-\mathrm{P} 4 \mathrm{VP}: \mathrm{PCBM}(\mathrm{C} 36)$ thin films after iodine staining and various annealing times at $150^{\circ} \mathrm{C}$ : a) the P3HT:PCBM reference film and b) C36 film after 30 min annealing; b) the reference and c) C36 films after $24 \mathrm{~h}$ annealing. Macrophase separation is observed only in the reference film (b), whereas the block copolymer nanostructure improves upon long-term annealing (d). Inset of c,d: the nanostructures of the pure block copolymer P3HT-P4VP after $30 \mathrm{~min}$ (c, inset) and $24 \mathrm{~h}$ (d, inset) annealing over a $200 \mathrm{~nm} \times 200 \mathrm{~nm}$ surface area.

copolymer morphology at $150^{\circ} \mathrm{C}$, it may be anticipated that devices made thereof will experience a significantly enhanced lifetime, in comparison to P3HT:PCBM reference devices, when used in typical solar cell operating conditions (temperature $\sim 60^{\circ} \mathrm{C}$ ).

Because the substrate-blend interface may have a nonnegligible influence on the thin film morphology in a PV device, we also investigated the TEM morphology of the copolymer blend in a real device configuration. Figure 3 shows the top view and cross-section of a C17 solar cell active layer in a standard device structure (Fig. 1b) annealed for $15 \mathrm{~min}$ at $140^{\circ} \mathrm{C}$. The PEDOT:PSS layer was dissolved in water, and the active layer was collected on a copper grid. The cross-section was performed below the aluminum top electrode. A nanostructure similar to the morphology given in Figure $2 \mathrm{~d}$ can be observed in both the in-plane (Fig. 3a) and out-of-plane (Fig. 3b) projections. This observation highlights the existence of an interpenetrated network of donor and acceptor nanodomains throughout the film thickness. However, close inspection of the active layer near the bottom interface, initially in contact with the PEDOT:PSS layer, reveals the existence of a rather uniform bright layer. The latter suggests the occurrence of preferential wetting of one of the copolymer blocks at the PEDOT:PSS interface during the film formation. In fact, complementary investigations using secondary ion mass spectroscopy (SIMS) provide evidence supporting the accumulation of P4VP at the PEDOT:PSS layer; these are discussed in the Supporting Information. This behavior corroborates the already reported tendency of polyvinylpyridine
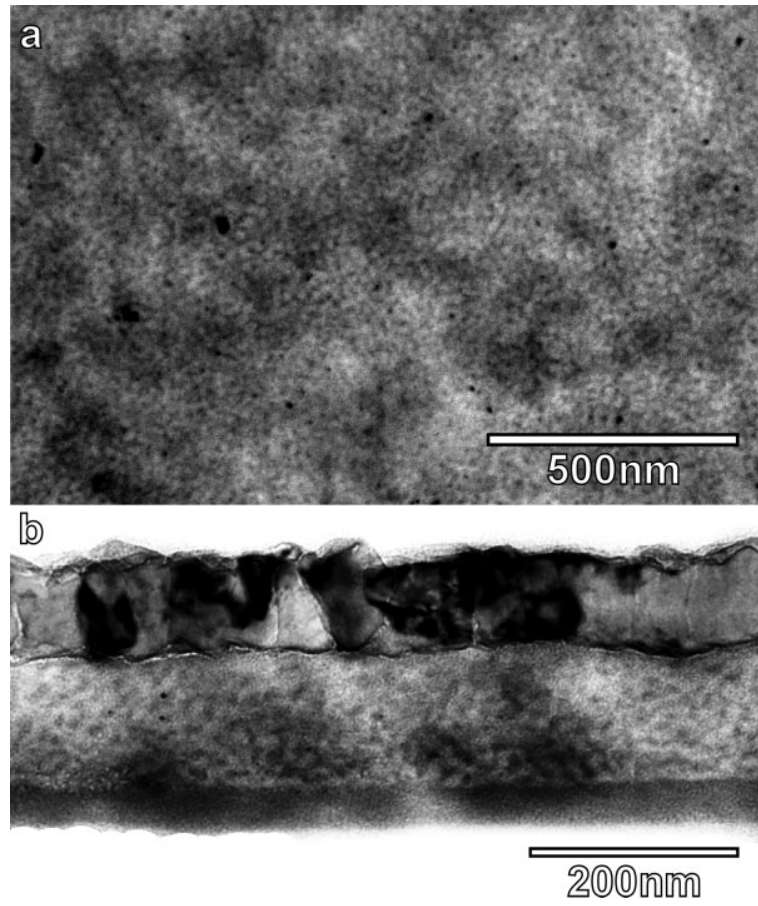

Figure 3. TEM images (iodine-stained) of the active layer of a $\mathrm{C} 17$ standard device. a) Top view of an Al-free region of the film, and b) device crosssection. The active layer exhibits the same percolating structure in lateral and perpendicular projections.

to preferentially wet oxide or charged surfaces. ${ }^{[41]}$ The impact of this layer on the device performances will be discussed below.

The UV-light absorption spectra of C17 and C36 thin films, before and after annealing at $150{ }^{\circ} \mathrm{C}$ for $24 \mathrm{~h}$, are given in Figure 4. Three absorption peaks located at 519, 555, and $603 \mathrm{~nm}$ can be seen and are similar to the spectral features frequently observed in rr-P3HT thin films. ${ }^{[42,43]}$ The P3HTabsorption peaks are known to be related to the vibronic splitting of the $\pi-\pi^{*}$ transition, and their amplitude ratio has been correlated before to the degree of polymer ordering. Their presence in the absorption spectra reflects a significant degree of structural ordering, which increases upon annealing, even for relatively high fullerene volume fractions (up to 36\%). This property is essential for the charge carrier mobility within block-copolymer films.

Both, TEM and spectroscopic results indicate the ability of P3HT-P4VP block copolymers to self-assemble into thermally stable nanostructured thin films consisting of ordered P3HT domains and PCBM-enriched P4VP domains. The preferential positioning of PCBM molecules within the coil domains will be further assessed through the PV device performances, since the latter are strongly dependent on the existence of percolating transport paths for both electrons and holes.

The IPCE for solar cells obtained with the standard device structure (Fig. 1b) were found to exceed $40 \%$ (see Supporting Information). Such high values indicate efficient exciton dissociation into free carriers and hence corroborate the conclusions from our structural investigations. Nonetheless, the PV performances of these devices turned out to be extremely 


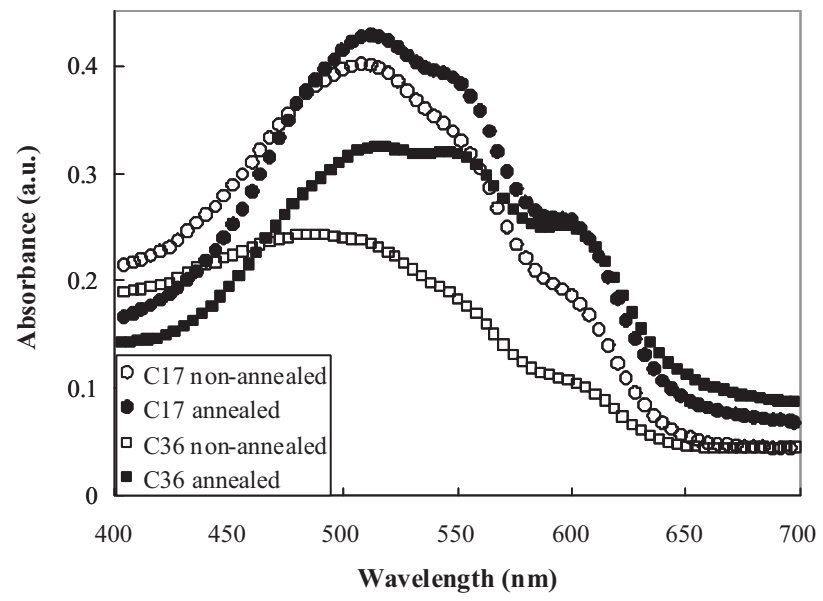

Figure 4. UV-vis absorption spectrum of $\mathrm{C} 17$ and $\mathrm{C} 36$ thin films on ITO substrates, before and after annealing for $24 \mathrm{~h}$ at $150^{\circ} \mathrm{C}$.

low, regardless of the PCBM content, as revealed by the current-voltage characteristics $(J-V)$ of the C36 device measured under AM1.5 illumination (Fig. 5a). Both, the fill-factors (FFs) and open-circuit voltages $\left(V_{\text {oc }}\right)$ did not exceed $30 \%$ and $0.33 \mathrm{~V}$, respectively, and decreased with increasing PCBM content. The resulting PCE remained below $0.03 \%$. Thermal annealing at $150{ }^{\circ} \mathrm{C}$ further decreased these values. (see Supporting Information for the detailed PV parameters).

These poor performances may be attributed to the presence of the P4VP-rich layer on top of the PEDOT:PSS layer, whose existence was supported by TEM and SIMS measurements discussed above. Indeed, the latter would lead to PCBM accumulation near the device anode and thereby introduce a hole collection barrier and/or interfacial dipoles. ${ }^{[4]}$ The barrier amplitude would depend on the PCBM volume fraction and vary with light intensity (through photo-inducted appearance of negatively charged fullerenes). Almost absent during the ICPE measurements (low intensity light), the barrier is expected to inhibit device operation under AM1.5 illumination (high intensity light).

In order to overcome this problem of charge collection efficiency at the electrodes, we tested the performances of P3HT-P4VP:PCBM active layers using an inverted device structure (Fig. 1c) in which the active layer was cast directly on top of the cathode, making irrelevant preferential wetting by the electron-transporting domains. Figure $5 \mathrm{~b}$ shows the $J-V$ diagram for such an inverted PV cell with a C36 active layer. The corresponding PV performances are summarized in Table 1. Unlike the previous case, excellent FF and $J(V)$ behavior were found, both prior and after the thermal annealing of the device. Furthermore, while the IPCE was almost identical to that of standard configuration, the PCE reached in the present case 1.2\% after annealing, without device optimization. These high values demonstrate that the optoelectronic properties of the blockcopolymer-based active layer are suitable for efficient solar cell devices. Importantly, extended annealing $\left(14 \mathrm{~h}\right.$ at $\left.150^{\circ} \mathrm{C}\right)$ did improve the PV performances of the inverted device, emphasizing the good thermal stability of the active layer morphology observed by TEM and suggesting an improved device operational lifetime.
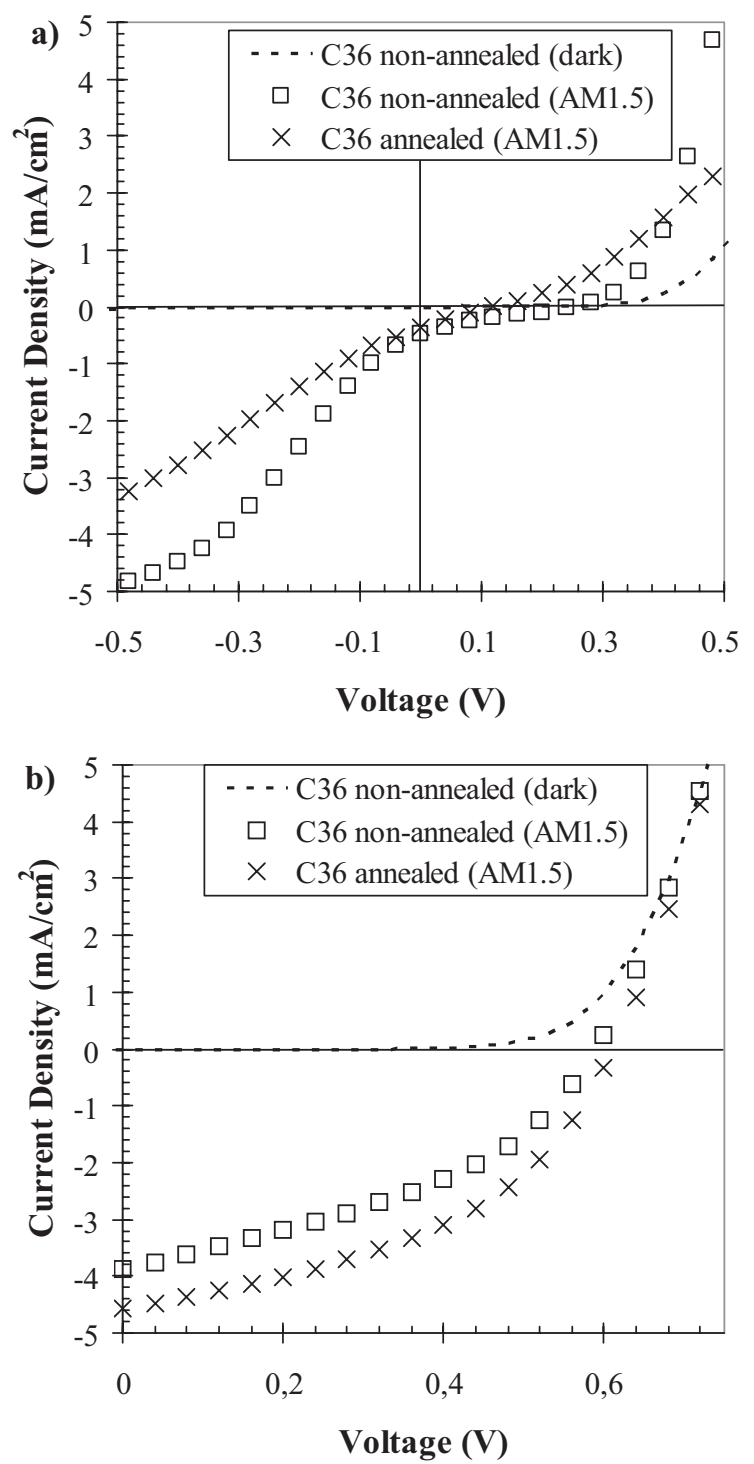

Figure 5. Current-voltage curves of a solar cell with a C36 active layer. Measurements were done under dark and under AM $1.5\left(100 \mathrm{~mW} \mathrm{~cm}^{-2}\right)$ illumination using either a) the standard or b) the inverted device structure. The measurements were done before and after annealing at $150^{\circ} \mathrm{C}$ for $12 \mathrm{~h}$ (in addition to the $15 \mathrm{~min}$ anneal at $150^{\circ} \mathrm{C}$ included in the device elaboration procedure).

Our results further exemplify the foremost importance of the metal/organic interfaces in the overall device operation. Indeed, while the "bulk" performance of the P3HT-P4VP:PCBM-based active layer is excellent (as revealed by the high IPCE) and insensitive on the device configuration, the final efficiency of the device can be exploited at best only by careful interfacial engineering.

In summary, we have proposed a new approach to design bicontinuous electron-donor/electron-acceptor networks based on rod-coil P3HT-P4VP block copolymers blended with PCBM via supramolecular weak interactions, in which the microphase segregated P3HT-rod domains act as electron-donating species and the homogeneous P4VP block:PCBM blend is the 
Table 1. PV performances of solar cells with inverted device structure, before and after annealing at $150^{\circ} \mathrm{C}$.

\begin{tabular}{lcccc}
\hline Before annealing & & & & \\
\hline Composition & $V_{\text {oc }}[\mathrm{V}]$ & $J_{\text {sc }}\left[\mathrm{mA} \mathrm{cm}^{-2}\right]$ & $\mathrm{FF}[\%]$ & PCE [\%] \\
$\mathrm{C} 17$ & 0.61 & 3.93 & 40.2 & 0.96 \\
$\mathrm{C} 36$ & 0.61 & 4.06 & 40.2 & 0.99 \\
After $14 \mathrm{~h}$ at $150^{\circ} \mathrm{C}$ & & & & \\
$\mathrm{C} 36$ & 0.62 & 4.51 & 43.8 & 1.22 \\
\hline
\end{tabular}

electron-acceptor counterpart. This approach allows the design of the optimal composition of the system for preserving both suitable structural morphologies and hole/electron mobilities. This settles the compositional/structural control well beyond the possibilities offered by block copolymers with covalently bound electron-acceptor moieties. By following this route, active layers for PV cells have been designed with highly improved thermal stabilities, photon-to-current conversion efficiencies equivalent to those of polymer heterojunction reference cells, and overall energy conversion efficiencies beyond those reported for PV cells whose active layer contain a block copolymer as its major constituent. Thus, the present approach can offer a new viable route toward the design of active layers for bulk heterojunction block-copolymer-based PV cells with improved stability and competitive optoelectronic properties.

\section{Experimental Section}

Materials: The copolymer was synthesized following a similar procedure to the one reported for the synthesis of PPV-P4VP block copolymers [18]. Details about the P3HT-P4VP synthesis will be reported in a separate article. In the present case, only $80 \%$ of the $\mathrm{P} 3 \mathrm{HT}$ polymers used were end-functionalized: the polymeric material was thus constituted of $80 \%$ of block copolymers and $20 \%$ of residual P3HT homopolymer. This excess homopolymer is expected to stabilize the nanodomains interfaces [17]. The 4-vinylpyridine block size was intentionally maintained short so that swelling of the coil phase by fullerenes does not jeopardize the possibility of thermodynamically stable interfaces. The blend of the $\mathrm{P} 3 \mathrm{HT}_{52}-\mathrm{P}_{4} \mathrm{VP}_{28}$ with $\mathrm{PCBM}$ was formed by mixing overnight adequate amounts of PCBM and P3HT-P4VP solutions in o-dichlorobenzene. The $\mathrm{PCBM}$ and the rr-P3HT, employed for the reference blends, were used as received.

TEM Sample Preparation: P3HT-P4VP:PCBM blend films were spincoated from a o-dichlorobenzene solution on top of a PEDOT:PSS layer previously deposited on a silicon wafer. By dissolving the PEDOT:PSS layer in water, the active layer is floated on water and recovered on a copper grid. The P4VP phase is stained with iodine for $4 \mathrm{~h}$ and micrographs are taken on a SIS Morada CCD mounted on a CM 100 Philips TEM operated at $80 \mathrm{kV}$.

Cross-Section Preparation: The aluminum electrode of the device is covered with the four components epoxy resins used for TEM samples preparation. After $3 \mathrm{~h}$ curing at $70^{\circ} \mathrm{C}$, the epoxy coated device is left in cold water until the PSS-PEDOT layer is dissolved by the water diffusing from the uncoated side of the device (typically a few hours). The epoxy layer with the organic film is then carefully recovered and embedded in epoxy resin to form a block which is used to produce ultrathin cut using a Leica Ultramicrotome.

Device Elaboration and Characterization Procedures: The device structure for the standard device configuration was glass/ITO/PEDOT:PSS/active layer/Ca/Al (Fig. 1b), while the inverted device structure was glass/ITO/ $\mathrm{TiO}_{x} /$ active layer/HTL/Al (Fig. 1c), where HTL represents a conductive polymer used as hole transporting layer. The PEDOT:PSS, HTL and $\mathrm{TiO}_{x}$ layers as well as the active layer were obtained by spin-coating. For the active layer deposition, a $25 \mathrm{mg} \mathrm{mL}^{-1}$ blend solution was used. All the samples were annealed at $150^{\circ} \mathrm{C}$ for $15 \mathrm{~min}$ prior to metal deposition. The metal electrodes were deposited by thermal evaporation. The device active area was $28 \mathrm{~mm}^{2}$. The whole process was done in a nitrogen filled glovebox.

The device current-voltage characteristics were measured under both, darkness and AM1.5 $\left(100 \mathrm{~mW} \mathrm{~cm}{ }^{-2}\right)$ illumination. J-V and ICPE measurements as well as device annealing $\left(150^{\circ} \mathrm{C}\right.$ for up to $\left.14 \mathrm{~h}\right)$ were performed under nitrogen atmosphere.

\section{Acknowledgements}

The authors acknowledge the Swiss Science National Foundation, BASF Aktiengesellschaft, and the French Agence Nationale de la Recherche (HABISOL program) for financial support. This work is dedicated to the memory of Dr. Bert de Boer, who has produced a deep and lasting contribution to the field of block copolymers in organic photovoltaics.

[1] H. Spranggaard, F. C. Krebs, Sol. Energy Mater. Sol. Cells 2004, 83, 125.

[2] C. W. Tang, Appl. Phys. Lett. 1986, 48, 183.

[3] B. C. Thompson, J. M. J. Frechet, Angew. Chem, Int. Ed. 2008, 47, 58.

[4] G. Dennler, M. C. Scharber, C. J. Brabec, Adv. Mater. 2009, 21, 1323.

[5] R. A. J. Janssen, J. C. Hummelen, N. S. Sariciftci, MRS Bull. 2005, 30, 33.

[6] G. Hadziioannou, MRS Bull. 2002, 27, 456.

[7] L. J. A. Koster, E. C. P. Smits, V. D. Mihailetchi, P. W. M. Blom, Phys. Rev. B 2005, 72, 085205.

[8] M. C. Scharber, D. Mühlbacher, M. Koppe, P. Denk, C. Waldauf, A. J. Heeger, C. J. Brabec, Adv. Mater. 2006, 18, 789.

[9] W. Ma, C. Yang, X. Gong, K. Lee, A. J. Heeger, Adv. Funct. Mater. 2005, 15, 1617.

[10] Y. Kim, S. Cook, S. Tuladhar, S. A. Choulis, J. Nelson, J. R. Durrant, D. D. C. Bradley, M. Giles, I. Mcculloch, C.-S. Ha, M. Ree, Nat. Mater. 2006, 5, 197.

[11] M. K. Riede, K. O. Sylvester-Hvid, M. Glatthaar, N. Keegan, T. Ziegler, B. Zimmermann, M. Niggemann, A. W. Liehr, G. Willeke, A. Gombert, Prog. Photovoltaics: Res. Appl. 2008, 16, 561.

[12] J. J. M. Halls, K. Pichler, R. H. Friend, S. C. Moratti, A. B. Homes, Appl. Phys. Lett. 1996, 68, 3120.

[13] D. E. Markov, J. C. Hummelen, P. W. M. Blom, A. B. Sieval, Phys. Rev. B 2005, 72, 045217.

[14] M. Reenders, G. ten Brinke, Macromolecules 2002, 35, 3266.

[15] B. D. Olsen, D. Alcazar, V. Krikorian, M. F. Toney, E. L. Thomas, R. A. Segalman, Macromolecules 2008, 41, 58.

[16] B. D. Olsen, R. A. Segalman, Macromolecules 2005, 38, 10127.

[17] N. Sary, R. Mezzenga, C. Brochon, G. Hadziioannou, J. Ruokolainen, Macromolecules 2007, 40, 3277.

[18] N. Sary, L. Rubatat, C. Brochon, G. Hadziioannou, J. Ruokolainen, R. Mezzenga, Macromolecules 2007, 40, 6990.

[19] N. Sary, C. Brochon, G. Hadziioannou, R. Mezzenga, Eur. Phys. J. E 2007, 24, 379.

[20] M. Sommer, S. M. Lindner, M. Thelakkat, Adv. Funct. Mater. 2007, 17, 1493.

[21] S. S. Sun, C. Zhang, A. Ledbetter, S. Choi, K. Seo, C. E. Bonner, M. Drees, N. S. Sariciftci, Appl. Phys. Lett. 2007, 90, 043117.

[22] G. Sauve, R. D. McCullough, Adv. Mater. 2007, 19, 1822.

[23] C. Brochon, N. Sary, R. Mezzenga, C. Ngov, F. Richard, M. May, G. Hadziioannou, J. Appl. Polym. Sci. 2008, 110, 3664.

[24] B. de Boer, U. Stalmach, P. F. van Hutten, C. Melzer, V. V. Krasnikov, G. Hadziioannou, Polymer 2001, 42, 9097.

[25] U. Stalmach, B. de Boer, C. Videlot, P. F. van Hutten, G. Hadziioannou, J. Am. Chem. Soc. 2000, 122, 5464. 
[26] U. Stalmach, B. de Boer, A. D. Post, P. F. van Hutten, G. Hadziioannou, Angew. Chem, Int. Ed. 2001, 40, 428.

[27] M. H. van der Veen, B. de Boer, U. Stalmach, K. Van de Wetering, G. Hadziioannou, Macromolecules 2004, 37, 3673.

[28] K. Van De Wetering, C. Brochon, C. Ngov, G. Hadziioannou, Macromolecules 2006, 39, 4289.

[29] J. S. Liu, E. Sheina, T. Kowalewski, R. D. McCullough, Angew. Chem, Int. Ed. 2002, 41, 329

[30] C. L. Chochos, J. K. Kallitsis, V. G. Gregoriou, J. Phys. Chem. B 2005, 109, 8755.

[31] P. K. Tsolakis, J. K. Kallitsis, A. Godt, Macromolecules 2002, 35, 5758.

[32] S. Kim, Y. Kakuda, A. Yokoyama, T. Yokozawa, J. Polym. Sci, Part A 2007, 45, 3129.

[33] F. Richard, C. Brochon, N. Leclerc, D. Eckhardt, T. Heiser, G. Hadziioannou, Macromol. Rapid Commun. 2008, 29, 885.

[34] S. Barrau, T. Heiser, F. Richard, C. Brochon, C. Ngov, K. Van de Wetering, G. Hadziioannou, D. V. Anokhin, D. A. Ivanov, Macromolecules 2008, 41, 2701.
[35] M. S. Rahman, S. Samal, J. S. Lee, Macromolecules 2006, 39, 5009.

[36] T. Heiser, G. Adamopoulos, M. Brinkmann, U. Giovanella, S. Ould-Saad, C. Brochon, K. Van de Wetering, G. Hadziioannou, Thin Solid Films 2006, 511, 219.

[37] M. Urien, H. Erothu, E. Cloutet, R. Hiorns, L. Vignau, H. Cramail, Macromolecules 2008, 41, 7033.

[38] A. Laiho, R. H. A. Ras, S. Valkama, J. Ruokolainen, R. Osterbacka, O. Ikkala, Macromolecules 2006, 39, 7648.

[39] N. Sary, L. Rubatat, C. Brochon, G. Hadziioannou, R. Mezzenga, Macromol. Symp. 2008, 268, 28.

[40] R. Mezzenga, J. Ruokolainen, G. H. Fredrickson, E. J. Kramer, D. Moses, A. J. Heeger, O. Ikkala, Science 2003, 299, 1872.

[41] S. Malynych, I. Luzinov, G. Chumanov, J. Phys. Chem. B 2002, 106, 1280.

[42] G. Li, V. Shrotriya, Y. Yao, J. Huang, Y. Yang, J. Mater. Chem. 2007, 17 , 3126.

[43] Z. Y. Zhou, X. W. Chen, S. Holdcroft, J. Am. Chem. Soc. 2008, 130, 11711.

[44] A. Kumar, S. Sista, Y. Yang, J. Appl. Phys. 2009, 105, 094512. 